\title{
Endoscopic submucosal dissection of a large malignant gastric hyperplastic polyp, developing on gastric amyloidosis, after endoscopic and echoendoscopic characterization
}

Gastric hyperplastic polyps are commonly found on upper endoscopy and are usually benign. However, rare cases of malignant transformation of hyperplastic polyps have been reported [1]. Localized gastric amyloidosis is a rare entity. Although the endoscopic appearance can sometimes mimic gastric cancer [2], the association of gastric amyloidosis and adenocarcinoma is uncommon.

We report the case of a 79-year-old woman with a history of gastric amyloidosis who was referred to our center for endoscopic evaluation and treatment of a large villous gastric lesion ( $>$ Fig. $1 \mathbf{a}-\mathbf{c}$ ).
Endoscopic ultrasound revealed a tumor that had spread mainly to the mucosal layer, with a small area corresponding to a macronodule that was in close contact, but not invading, the muscular layer. We performed an endoscopic submucosal dissection (ESD) and, although the procedure was particularly difficult because of important areas of submucosal fibrosis, we removed the lesion en bloc in a specimen measuring $170 \times 140 \mathrm{~mm}(\triangleright$ Fig. 2 a, - Video 1). Some isolated points of contact with the superficial muscle layer were closed using hemostatic clips ( Fig.1d).

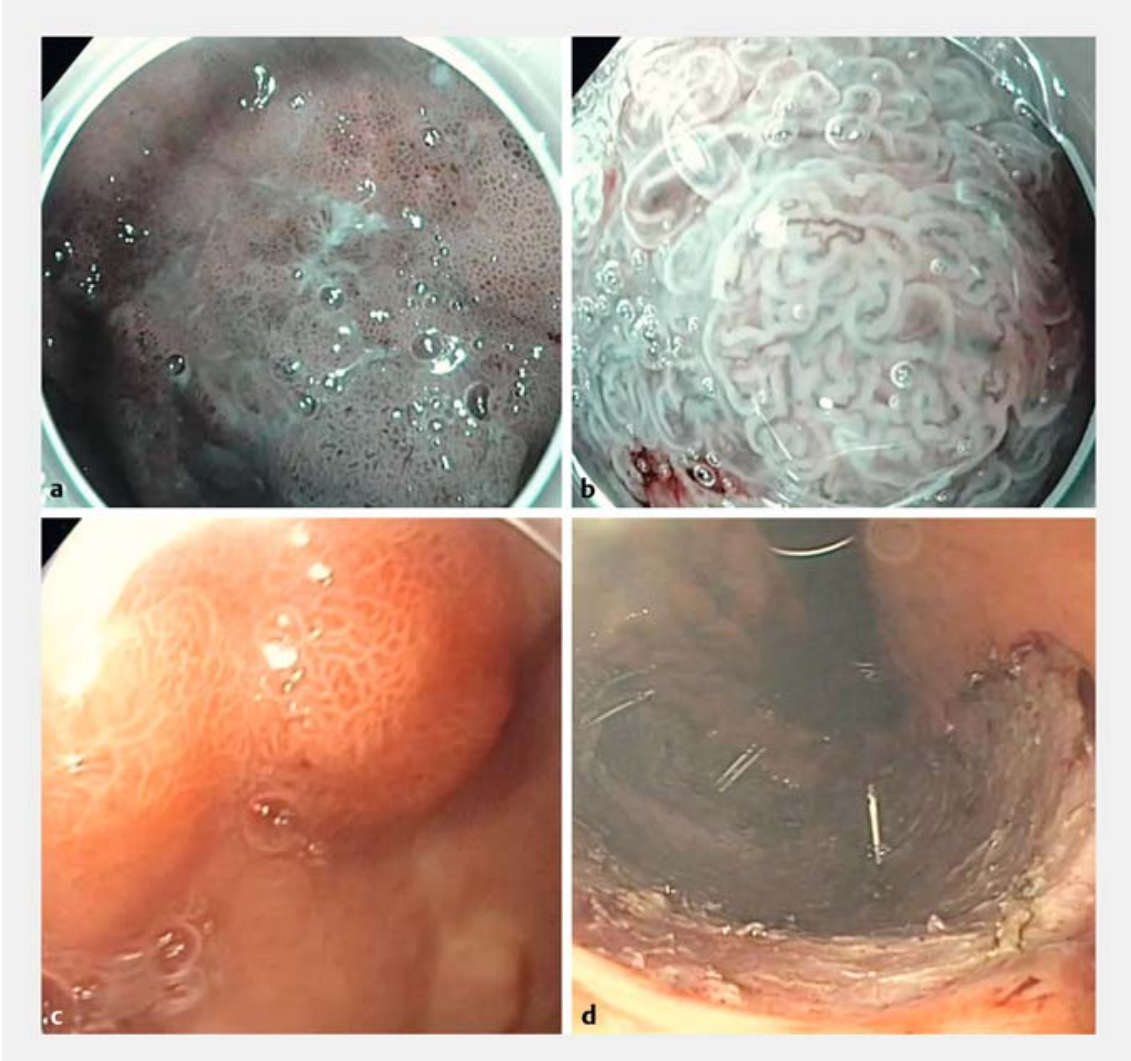

- Fig. 1 Aspect of the gastric lesion before (a, b, c) and after (d) endoscopic submucosal dissection (ESD). a Narrow-band imaging (NBI). b Zoom NBI. c Macroscopic appearance without NBI. d The mucosal defect after ESD, with hemostatic clips.
The histopathology analysis confirmed an atypical hyperplastic polyp with areas of low and high grade dysplasia and intramucosal adenocarcinoma, as well as gastric amyloidosis in the submucosa ( Fig.2b-d). No Helicobacter pylori was detected, and after multidisciplinary discussion endoscopic surveillance was decided [3].

One case of gastric adenocarcinoma coexisting with gastric amyloidosis has previously been reported [4], but to the best of our knowledge this is the first case of endoscopic diagnosis and ESD of a malignant hyperplastic polyp developing on gastric amyloidosis. The procedure was particularly difficult due to important submucosal fibrosis, but the resection was confirmed as R0 after histopathology analysis, with no further complication. In conclusion, for large gastric hyperplastic polyps, ESD is possible even in the presence of gastric amyloidosis with important submucosal fibrosis.

Endoscopy_UCTN_Code_TTT_1AO_2AG

Competing interests

None

The authors

Marina Ciochina', Alexandru Lupu², Valérie Hervieu$^{3}$, Jérôme Rivory ${ }^{1}$, Florian Rostain ${ }^{1}$, Jean Christophe Valats ${ }^{4}$, Mathieu Pioche ${ }^{1}$

1 Department of Endoscopy and Gastroenterology, Pavillon L, Edouard Herriot Hospital, Lyon, France

2 Gastroenterology Department, Fundeni Hospital, Bucharest, Romania

3 Pathology Department, Hospices Civils de Lyon, Lyon, France

4 Department of Endoscopy and Gastroenterology, Lapeyronie Hospital, Montpellier, France 

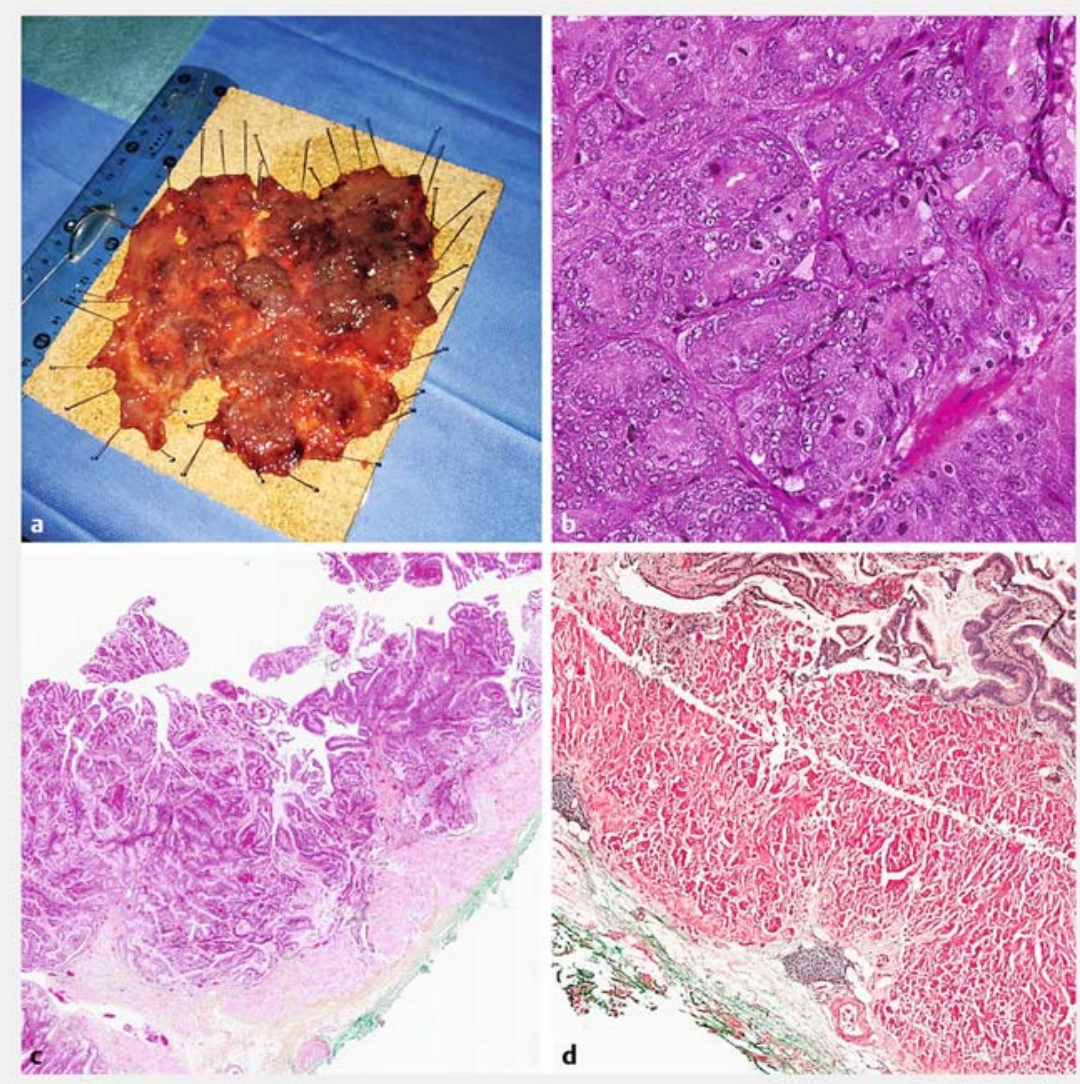

- Fig. 2 After endoscopic submucosal dissection. a Resection piece. b, c, $\mathbf{d}$ Histopathology of the gastric lesion, showing atypical cells and mitosis (b), hyperplastic polyp and amyloidosis (c; hematoxylin and eosin stain), and gastric amyloidosis (d; Congo red stain).

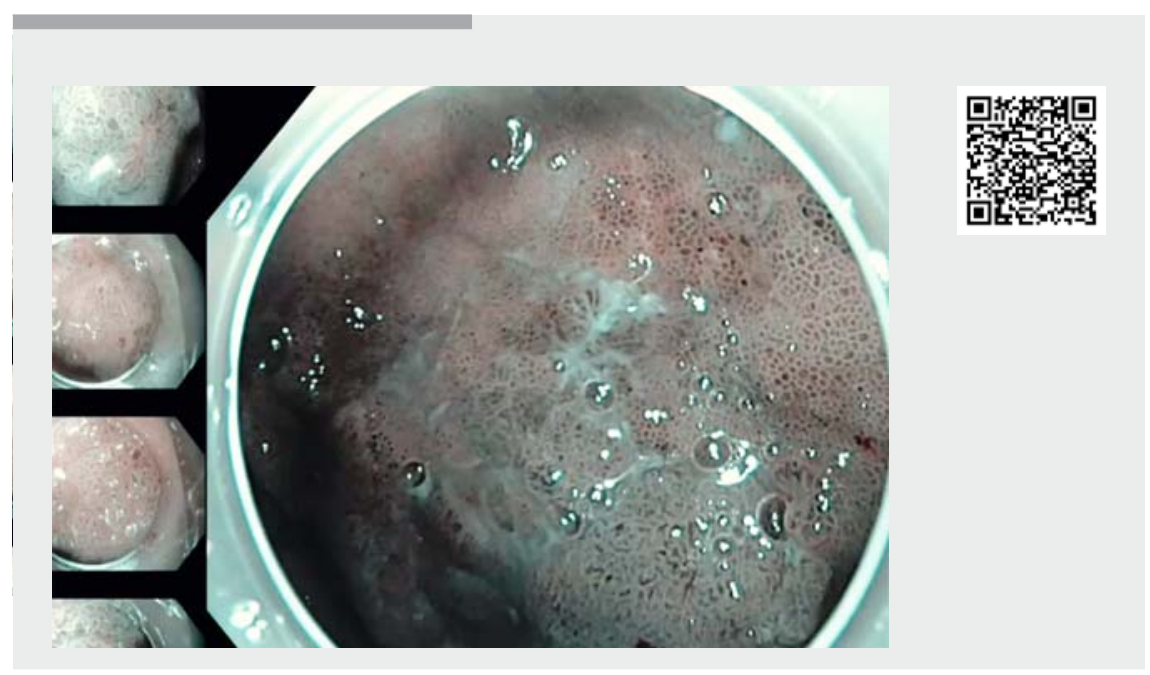

$\checkmark$ Video 1 Endoscopic submucosal dissection of a large malignant gastric hyperplastic polyp.
Corresponding author

\section{Mathieu Pioche, MD}

Endoscopy unit - Digestive Disease

Department, Pavillon L - Edouard Herriot

Hospital, 69437 Lyon Cedex, France

Fax: +33-4-72110147

mathieu.pioche@chu-lyon.fr

\section{References}

[1] Jain R, Chetty R. Gastric hyperplastic polyps: a review. Dig Dis Sci 2009; 54: 1839-1846

[2] Ortiz S, Tortosa F. Gastric amyloidosis mimicking a gastric neoplasm. Arch Case Rep Clin Med 2017; 3: 133

[3] Shaib YH, Rugge M, Graham DY et al. Management of gastric polyps: an endoscopybased approach. Clin Gastroenterol Hepatol 2013; 11: 1374-1384

[4] Aoyagi K, Koufuji K, Yano S et al. Early gastric carcinoma associated with amyloidosis: a case report. Kurume Med J 2002; 49: $153-156$

\section{Bibliography}

DOI https://doi.org/10.1055/a-0929-5842

Published online: 7.6.2019

Endoscopy 2019; 51: E352-E353

(c) Georg Thieme Verlag KG

Stuttgart · New York

ISSN 0013-726X

\section{ENDOSCOPY E-VIDEOS}

https://eref.thieme.de/e-videos

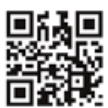

Endoscopy E-Videos is a free access online section, reporting on interesting cases and new techniques in gastroenterological endoscopy. All papers include a high quality video and all contributions are freely accessible online.

This section has its own submission website at

https://mc.manuscriptcentral.com/e-videos 